\title{
LOS RETOS AMBIENTALES Y SOCIALES DE LA REACTIVACIÓN ECONÓMICA POST CUARENTENA
}

\author{
César Leonidas Gamboa Balbín \\ Director Ejecutivo, Derecho Ambiente y Recursos Naturales (DAR)
}

Resumen: La pandemia del COVID-19 ha generado una crisis humanitaria y económica a nivel global, y Perú, especialmente, ha sido golpeado por este virus. Después de la finalización de la cuarentena (01 de julio), la nueva normalidad ha impuesto nuevas reglas de convivencia - como el distanciamiento social-, y bajo la presión de diversos actores económicos, el Gobierno peruano viene impulsando un plan de reactivación económica en cuatro fases controladas para acelerar el crecimiento económico que ha decaído en $15 \%$ del PBI. Sin embargo, el costo de esta reactivación se viene centrando en impactos ambientales y sociales de las inversiones. En ese sentido, analizaremos cómo los antecedentes de planes de recuperación económica (2013), el contexto político en el que vivimos y el nuevo marco legal —así como propuestas de normaspueden contribuir a un mayor impacto ambiental y social. No solo mostraremos que tienen una inconsistencia normativa con la regulación que las precedió, sino que no hay certeza de la efectividad de su cometido, poder reactivar la economía peruana desde criterios de sostenibilidad y un enfoque de derechos humanos.

Palabras Clave: COVID-19, reactivación económica, participación ciudadana, evaluación y fiscalización ambiental, áreas naturales protegidas. 


\title{
The Post-Quarantine Economic Reactivation Environmental and Social Challenges
}

\begin{abstract}
The COVID-19 pandemic has generated a humanitarian and economic crisis globally, and especially Peru has been hit by this virus. After the quarantine finished (July first), the new normal has imposed new rules of coexistence, such as social distancing. Simultaneously, under pressure from various economic keyactors, the Peruvian Government has been promoting an economic reactivation plan in 4 controlled phases to accelerate economic growth that has fallen by $15 \%$ of GDP for the next five years. However, this economic reactivation plan has a potential cost on the investments' environmental and social impacts. In this sense, we will analyze how the antecedents of economic recovery plans (2013), the political context in which we live, and the new legal framework and proposed regulations can contribute to a more significant environmental and social impact. We will not only show that they have a normative inconsistency with the rule that preceded them, but that there is no certainty of the effectiveness of their mission to be able to reactivate the Peruvian economy from sustainability criteria and a human rights approach.
\end{abstract}

Keywords: COVID-19, economic reactivation, citizen participation, environmental evaluation and control, protected areas.

\section{César Leonidas Gamboa Balbín}

Abogado y Doctor en Derecho y Ciencia por la Universidad Nacional Mayor de San Marcos. Director ejecutivo de Derecho, Ambiente y Recursos Naturales (DAR). Profesor de docencia continua y miembro del Grupo de Derecho Ambiental del INTE-PUCP. Miembro del Consejo Internacional de la Iniciativa para la Transparencia de las Industrias Extractivas (EITI por sus siglas en inglés) (2016-2022), del Board de la organización americana Bank Information Center (BIC) y del Comité Consultivo del Fondo Casa de Brasil.

Correo: cgamboa@dar.org.pe 


\section{Introducción}

Lo que estamos viviendo no tiene parangón con alguna otra experiencia reciente. Las generaciones jóvenes no vivieron los estragos del terrorismo en los ochenta ni el autoritarismo de los noventa. La pandemia del COVID-19 es inédita y no solo ha manifestado nuestras desigualdades o limitado nuestras libertades, sino que ha establecido nuevas reglas de convivencia para el futuro; es decir que tendrán que ser incorporadas en toda actividad política, social y económica de nuestra sociedad.

Muchos dirán que la pandemia del COVID-19 es uno de los males «más democráticos» posibles porque puede afectar a cualquiera. Hasta ahora, se conoce que los pacientes con potenciales riesgos (por ejemplo: diabéticos, hipertensos o personas con obesidad) son los más afectados; sin embargo, por azar, puede afectar a cualquiera y aún no hay una vacuna para protegernos. Posterior a una cuarentena fallida, se han impuesto nuevas reglas para todos, que incluyen nuevas reglas de convivencia basadas en el distanciamiento social. Lo cierto es que al igual que los efectos del cambio climático, el COVID-19 no afectará a los países ni a los ciudadanos por igual (Welzer 2010: 134). En la actualidad, no afecta a todos los peruanos de la misma manera, porque somos «una sociedad que mantiene elevadas desigualdades en la riqueza y los ingresos» (Alarco et al. 2019: 155), afectando a los que no han accedido a muchos (ingresos), es decir, a los más pobres, quienes son los que están más expuestos a esta enfermedad ${ }^{1}$.

Bajo esta «nueva normalidad» uno de los elementos más importantes: el cómo volver a la senda del crecimiento económico, se vuelve impositivo para el país. De hecho, ya no hay mucho espacio para discursos «cuestionadores» que demanden transiciones al desarrollo como «erradicar la pobreza y evitar nuevas extinciones de biodiversidad» (Gudynas 2012: 103); incluso propuestas tradicionales del desarrollo sostenible son casi una narrativa «radical» de ciertos grupos aún preocupados por el respeto de los estándares ambientales y sociales o la obligatoriedad de la evaluación ambiental antes de cualquier operación, para evitar mayores daños a los ecosistemas, pueblos indígenas, comunidades locales y ciudadanos en general.

\footnotetext{
1 El Sistema Informático Nacional de Defunciones del MINSA (sistema de datos abiertos) ha reportado al 21 de junio «los determinantes sociales de salud, nivel educativo de fallecidos por COVID 19 en Lima», en el cual se puede identificar que el número de fallecidos con secundaria o menos llega alrededor de 400 en promedio, mientras que el número de fallecidos con educación superior no supera los 50 en promedio, desde el inicio de la cuarentena (MINSA 2020).
} 
La actual agenda política arguye que tan solo debemos aspirar a seguir creciendo en el siguiente lustro, cueste lo que cueste. El objetivo es llevar pan a la casa para la mayoría de los peruanos, «sacrificando la salud del mañana, o nuestros ecosistemas, para satisfacer el hambre del hoy». Claramente, es algo que no tiene nada de sostenible e incluso, en un futuro, podría ser debatible si es una fórmula efectiva.

Pero no es lo único que se pretende sacrificar. De hecho, la preocupación de la sostenibilidad de las actividades económicas también va de la mano con posibles restricciones al ejercicio de derechos, los cuales son vistos como obstáculos para el desarrollo de las inversiones, o al menos su ralentización en la última década, sostenido principalmente por el sector privado. Como veremos, ello tampoco es tan cierto.

En consecuencia, analizaremos particularmente uno de los efectos de la propuesta gubernamental de reactivación económica desde la perspectiva ambiental y de derechos: los cambios o introducciones legales cuya afectación esté relacionada al ejercicio de derechos ambientales e indígenas en la última década. No solo mostraremos que tienen una inconsistencia normativa con la regulación que las precedió, sino que no hay certeza de la efectividad de su cometido.

\section{Antecedentes: paquetazos ambientales y el Tribunal Constitucional}

A la par de un discurso gubernamental político y técnico para salir de la parálisis económica producto de la pandemia — se han expuesto varias veces los objetivos de las cuatro fases de la reactivación económica - el discurso actual que sostiene la «reactivación económica», posterior al periodo de cuarentena en el Perú (del 15 de marzo al 30 de junio), tiene muchas semejanzas con lo sucedido en 2013, es decir, no solo la influencia del sector privado en la agenda pública, sino también la necesidad de que las actividades productivas se reinicien sin tomar en cuenta el costo en salud o incluso ambiental ${ }^{2}$.

En 2013, producto de la desaceleración económica de China y su decisión de inversión interna para hacer crecer su economía doméstica, los precios de los commodities cayeron y con ello acabó un súperciclo del auge del precio de los metales, el cual afectó a la economía mundial y, al tener una economía globalizada, también al Perú. En menos de un mes, a través de una campaña publicitaria, el sector privado presionó al gobierno de Ollanta Humala para que se adoptara una serie de medidas, las cuales han sido denominadas como las normas de los «paquetazos ambientales»: decreto supremo 54-2013-PCM,

2 En mayo, el diario Gestión, a través de la noticia «Confiep sobre protocolos de seguridad: están llenos de requisitos, parece para un país europeo», señaló la posición del gremio empresarial sobre las medidas que el Ejecutivo impuso como requisitos para la reactivación económica (Gestión 2020a). 
decreto supremo 60-2013-PCM, ley 30230 (Gamboa 2017: 157-8). La idea era permitir que nuestra economía sea más atractiva para las inversiones extranjeras, ser más competitivos (Solano et al. 2017: 381), aunque muchas de estas normas estaban orientadas a reducir tributos (De Echave y Flores 2020: 17) o a reducir los costos de operaciones de proyectos que se estaban desarrollando en ese momento, especialmente para favorecer el sector minero.

La elaboración y pronta publicación de estas normas, tal como lo ha señalado Durand (2016: 57), respondió a la presión de los sectores empresariales y permitió evidenciar la práctica de «puerta giratoria». Lo cierto es que se aprobaron estas disposiciones (ley 30230) sin tener una claridad de sus efectos, en particular, en la gobernanza de los recursos naturales.

Estas normas han diluido o limitado las facultades y competencias del sector ambiental en aspectos de gestión ambiental, instrumentos de control, prevención, fiscalización y de creación de áreas protegidas. Específicamente, respecto de la ley 30230, presentamos de manera sucinta los cambios incorporados. 
Tabla 1

\begin{tabular}{|c|c|}
\hline \multicolumn{2}{|c|}{ Instrumentos de gestión ambiental afectados por la Ley 30230 (2014) } \\
\hline De planeamiento & $\begin{array}{l}\text { En el caso del ordenamiento territorial (art. 22), señala que «ni la } \\
\text { Zonificación Económica Ecológica ni el Ordenamiento Territorial } \\
\text { asignan usos ni exclusiones de uso». }\end{array}$ \\
\hline De control & $\begin{array}{l}\text { Señala la norma que «los Estándares de Calidad Ambiental (ECA) } \\
\text { y Límites Máximos Permisibles (...), se efectuará mediante Decreto } \\
\text { Supremo refrendado por los sectores vinculados (...)». }\end{array}$ \\
\hline De prevención & $\begin{array}{l}\text { En el caso de la evaluación ambiental, se señala que se solicitará } \\
\text { a otros sectores por parte de la entidad principal del Estudio de } \\
\text { Impacto Ambiental (EIA), «opiniones vinculantes y no vinculantes», } \\
\text { «estas deberán emitirse, bajo responsabilidad, en un plazo máximo } \\
\text { de } 45 \text { días». }\end{array}$ \\
\hline De fiscalización & $\begin{array}{l}\text { En el caso de la fiscalización ambiental, «establécese un plazo de tres } \\
\text { (3) años contados a partir de la vigencia de la presente Ley, durante } \\
\text { el cual el Organismo de Evaluación y Fiscalización Ambiental - OEFA } \\
\text { privilegiara las acciones orientadas a la prevención y corrección de la } \\
\text { conductora infractora en materia ambiental. Durante dicho periodo, } \\
\text { el OEFA tramitara procedimientos sancionatorios excepcionales. Si } \\
\text { la autoridad administrativa declara la existencia de una infracción, } \\
\text { ordenará la realización de medidas correctivas a revertir la } \\
\text { conductora infractora y suspenderá el procedimiento sancionador } \\
\text { excepcional». }\end{array}$ \\
\hline $\begin{array}{l}\text { De conservación de } \\
\text { biodiversidad }\end{array}$ & $\begin{array}{l}\text { En el caso de áreas protegidas (art. 20), señala «por Decreto Supremo } \\
\text { con el voto aprobatorio del Consejo de Ministros se establecen las } \\
\text { Zonas Reservadas (...)». }\end{array}$ \\
\hline
\end{tabular}

Fuente: ANC et al. (2014). Elaboración propia.

Lo que produjeron estos cambios legales fue desconfianza y una permanente crítica de la sociedad civil de cómo se conciben las relaciones de poder e influencia entre distintos actores, y en particular el involucramiento de la ciudadanía para encontrar soluciones económicas que nos afectan a todos. Lo más grave de estas normas fue acuñado por la sociedad civil, como la promoción de la «impunidad ambiental» (Gamboa 2017: 167), especialmente por la limitación de la potestad sancionatoria del OEFA (ANC et al. 2014: 42).

La desconfianza vino alimentada con una falta de evidencia de que dichos cambios en la legislación ambiental produjeran algún resultado económico para el sector empresarial extractivo. En otras palabras, las crisis económicas del Perú no han provenido de conspiraciones internas que hayan jaqueado algún gobierno de turno. Alarco ha señalado reiteradas veces que la debilidad de la economía peruana no se debe a «la tramitología o la burocracia, que, a juicio de la mayor parte de los empresarios, empresas consultoras y el Gobierno, explicarían los bajos niveles de inversión privada y de producción en el Perú» (2017: 286-7). Las soluciones pueden encontrarse de donde vinieron los problemas económicos, es decir, del mercado internacional. Es más, Alarco señala que «la inversión privada, de acuerdo a evidencias internacionales, depende más de la evolución de los precios externos 
de las materias primas y de sus condiciones de financiamiento» (2017: 298), debido a la dependencia de nuestro modelo primario exportador, pues vendemos «piedras y agua». En consecuencia, desde el análisis de la economía nacional, se nos indica que el proceso de flexibilización ambiental iniciado en 2013 no era la solución para conseguir el tan ansiado crecimiento económico.

Como colofón a las críticas a la Ley 30230, tanto el Gobierno Regional de San Martín (diciembre de 2014), como las organizaciones indígenas y de sociedad civil, y cinco mil ciudadanos (abril de 2015) —impulsados por el Grupo de Trabajo sobre Pueblos Indígenas de la Coordinadora Nacional de Derechos Humanosinterpusieron demandas de inconstitucionalidad ante el Tribunal Constitucional. El Tribunal emitió sentencia y esta fue publicada el 12 de junio de este año (2020); es decir, luego de más de cinco años desde la interposición de ambas demandas. Lo cierto es que dicha sentencia declara la constitucionalidad de la Ley 30230, dicho de otro modo, no vulnera el derecho a un medio ambiente sano y equilibrado. Una lectura rápida de la sentencia señala que no se realizó un análisis riguroso de los argumentos de los peticionarios (Calle et al. 2020: 24), así como tampoco se analizaron las consecuencias formales y prácticas de dicha ley. No obstante, lo que sí queda claro es que el máximo intérprete de la Constitución incluyó el contexto del COVID-19 y su impacto en la economía nacional, es decir, se tuvo que alinear bajo la presión empresarial y los planes de reactivación económica (iniciativa del Gobierno) para mostrar que cualquier cambio futuro del marco legal, respecto a relajar los estándares ambientales y facilitar las inversiones — por ejemplo, la relajación de la fiscalización ambiental del OEFA — , podría contar con la seguridad jurídica de este antecedente decisorio. El debate de la sentencia del 12 de mayo, así como su difusión en junio, es un claro precedente para cualquier intento de demandar la inconstitucionalidad de normas ambientales ante los momentos excepcionales que vivimos.

\section{Reactivación económica: pilares extractivistas}

Los discursos políticos alrededor de la reactivación económica han mostrado un desbalance entre lo que se considera importante y lo urgente. El hecho de que el Congreso de la República le negara el voto de confianza al efímero gabinete liderado, hasta el 6 de agosto del presente año, por Pedro Cateriano, es el resultado de que haya resaltado en su discurso la priorización de la inversión minera para la reactivación; esto le pasó factura, pues ha sido uno de los pocos consejos de ministros que ha durado menos de un mes en los últimos veinte años de vida democrática, lo cual ha sido exacerbado por la crisis política y la incertidumbre frente a la pandemia.

La corrupción y falta de transparencia, así como la atención a los impactos ambientales y sociales, son ausencias claras de los planes de recuperación económica. En el primer caso, el Perú tiene una «mochila pesada» de la cual no puede desembarazarse fácilmente. No es solo que la historia republicana está 
asociada con la corrupción en una serie de ciclos de lucha contra este mal (Quiroz 2019: 368), sino que el inicio del periodo democrático del 2000 ha sido una tensión de reacomodos entre la «adaptación oportunista de intereses corruptos» y los frenos institucionales a esta «corrupción desenfrenada», factores que pueden verse representados en miniciclos más intensos a lo largo de los últimos veinte años.

Estos hechos de corrupción no son ajenos. A decir verdad, seguimos viviendo sus impactos en la economía; en la confianza entre la sociedad, el aparato burocrático y el sector empresarial, e incluso afectando a la elite política peruana. El caso de la constructora brasileña Odebrecht no es un caso aislado, sino de una forma de hacer negocios que el Estado permite porque sus controles de prevención no funcionan. Después de una serie de denuncias e involucramiento de empresas peruanas en procesos judiciales y de autoridades peruanas a nivel local, regional y nacional (Chávez 2018: 155-252), el efecto político y económico es devastador. Tal como señala Durand, «la colusión y la corrupción sacrifican el desarrollo por un crecimiento a cualquier costo, que deja herencia de una duplicidad jurídica, un fuerte daño reputacional e institucional que atraviesa toda la sociedad» (2018: 288). En el discurso dado por Cateriano ante el Congreso solicitando voto de confianza ( 3 de agosto), el efímero primer ministro mencionaba que la lucha contra la corrupción se plasmará a través del avance de las obras en un «Portal Nacional de Datos Abiertos de la Presidencia del Consejo de Ministros»; mientras que, poco después (11 de agosto), el actual primer ministro, Martos, no mencionaba nada sobre la lucha contra la corrupción.

La otra ausencia más notoria de la narrativa de la reactivación económica es su enfoque de derechos. Este hecho político no está aislado a lo que venimos viviendo desde el inicio de la cuarentena en la quincena de marzo. La tensión que se genera entre la promoción de la inversión, para mejorar nuestra situación económica, y las medidas para proteger la salud de la ciudadanía, especialmente la de los más vulnerables (trabajadores, pensionistas, mujeres, indígenas, defensores de derechos humanos, gente en extrema pobreza, entre otros), ha sido una constante. Ciertamente, uno puede encontrar en el debate político, y especialmente el congresal, varios hechos que evidencian esta tensión entre reactivación económica y derechos:

- La mínima asertividad de las políticas y medidas sanitarias para las comunidades campesinas y nativas, durante y después de la cuarentena; especialmente la tardía aprobación de un plan de protección para pueblos indígenas ${ }^{3}$.

3 Decreto legislativo $1489(10 / 05 / 20)$ que establece acciones para la protección de los pueblos indígenas u originarios como parte de la Emergencia Sanitaria declarada por el COVID-19. Con fecha posterior, se aprobó el plan de intervención para comunidades indígenas y centros poblados rurales de la Amazonía frente a la emergencia del nuevo coronavirus (COVID-19), mediante resolución ministerial 308-2020-MINSA (21/05/20). 
- $\quad$ El debate político y congresal sobre el proyecto de ley que declara la intangibilidad de reservas indígenas para pueblos indígenas en situación de aislamiento y en situación de contacto inicial (PIACI), que trajo como consecuencia la oposición del Ministerio de Energía y Minas ${ }^{4}$ y del sector empresarial en el Perú.

- El inicio del debate político sobre la consulta previa que va desde reformar el marco legal y expandir su aplicación, hasta adecuarla a la nueva realidad a través de su «virtualización».

- $\quad$ El debate político centrado en la aprobación del Acuerdo de Escazú por parte del Congreso de la República6 .

De manera específica, en las propuestas políticas y legales relacionadas con la reactivación económica y la perspectiva ambiental y social, podemos encontrar que el foco de la reactivación será la actividad extractiva; tal como se viene dando en los cambios legales de ciertos sectores como hidrocarburos, forestal y minero, este último resaltado en el discurso del expremier Cateriano. Aprovechar la oportunidad de la diversificación productiva de nuestra economía y del plan de 2014 (Machado 2014: 37) quedó atrás, así como otras propuestas de innovación e inversión en tecnología y conocimiento. En la siguiente tabla mencionaremos las normas más importantes para los planes de recuperación económica, pues en total estamos hablando de más de cien normas aprobadas en los últimos cinco meses.

\footnotetext{
Para mayor información consultar el diario Gestión (2020b).

5 Para mayor información consultar RPP Noticias (2020).

6 Se ha generado un debate polarizado y equivocado alrededor del Acuerdo de Escazú (2018), que trata sobre derechos de participación y acceso a la información y a la justicia ambiental y no sobre la pérdida de la soberanía. Para una lectura del diálogo en el seno de la Comisión de Relaciones Exteriores del Congreso véase la documentación en el portal online del Congreso de la República (consultar referencias al final de este artículo).
} 
Tabla 2

\begin{tabular}{|c|c|}
\hline & Normativa de la Reactivación Económica \\
\hline \multirow[t]{3}{*}{$\begin{array}{l}\text { Reactivación } \\
\text { económica de } \\
\text { proyectos de } \\
\text { inversión en el } \\
\text { marco del impacto } \\
\text { de la pandemia }\end{array}$} & $\begin{array}{l}\text { DS } 080-2020-P C M, \text { que aprueba la reanudación de actividades } \\
\text { económicas en forma gradual y progresiva dentro del marco de } \\
\text { la declaratoria de Emergencia Sanitaria Nacional por las graves } \\
\text { circunstancias que afectan la vida de la Nación a consecuencia del } \\
\text { COVID-19. }\end{array}$ \\
\hline & $\begin{array}{l}\text { RM 0257-2020-MTC/01. Protocolos Sanitarios Sectoriales que } \\
\text { como Anexos forman parte integrante de la presente Resolución } \\
\text { Ministerial. }\end{array}$ \\
\hline & $\begin{array}{l}\text { RM 128-2020-EM. Protocolo Sanitario para la Implementación } \\
\text { de medidas de prevención y respuesta frente al COVID } 19 \text { en las } \\
\text { actividades del Subsector Minería, el Subsector Hidrocarburos y el } \\
\text { Subsector Electricidad. }\end{array}$ \\
\hline $\begin{array}{l}\text { Reactivación } \\
\text { del sector } \\
\text { infraestructura }\end{array}$ & $\begin{array}{l}\text { DL } 1500 \text {, que establece medidas especiales para reactivar, mejorar y } \\
\text { optimizar la ejecución de los proyectos de inversión pública, privada } \\
\text { y público privada ante el impacto del COVID-19. }\end{array}$ \\
\hline \multirow[t]{2}{*}{$\begin{array}{l}\text { Reactivación del } \\
\text { sector minero }\end{array}$} & $\begin{array}{l}\text { DS 019-2020-EM, modificación al Reglamento de Exploraciones } \\
\text { Mineras: Decreto Supremo que modifica el Reglamento de Protección } \\
\text { Ambiental para las Actividades de Exploración Minera. }\end{array}$ \\
\hline & $\begin{array}{l}\text { DS 020-2020-EM que aprueba el Reglamento de Procedimientos } \\
\text { Mineros. }\end{array}$ \\
\hline Gestión ambiental & $\begin{array}{l}\text { RM 108-2020- MINAM «Disposiciones para realizar el trabajo de } \\
\text { campo en la elaboración de la línea base de los instrumentos de } \\
\text { gestión ambiental». }\end{array}$ \\
\hline \multirow[t]{2}{*}{$\begin{array}{l}\text { Fiscalización } \\
\text { ambiental }\end{array}$} & $\begin{array}{l}\text { Resolución del Consejo Directivo 007-2020-OEFA/CD, } \\
\text { «Procedimiento de aplazamiento de la exigibilidad del pago de } \\
\text { multas impuestas por el Organismo de Evaluación y Fiscalización } \\
\text { Ambiental - OEFA en el marco de la Emergencia Nacional». }\end{array}$ \\
\hline & $\begin{array}{l}\text { Resolución de Consejo Directivo 008-2020-OEFA/CD, que aprueba el } \\
\text { «Reglamento de Acciones de Fiscalización Ambiental y seguimiento } \\
\text { y verificación a Entidades de Fiscalización Ambiental del Organismo } \\
\text { de Evaluación y Fiscalización Ambiental - OEFA durante el Estado de } \\
\text { Emergencia Sanitaria». }\end{array}$ \\
\hline
\end{tabular}

Fuente: Portugal y Sembrero (2020). Elaboración propia

En consecuencia, hasta la fecha solo los sectores de infraestructura y minero han tenido ya normas específicas que modifican sus procedimientos en materia de licenciamiento ambiental. No obstante, también se han producido modificaciones en la propia gestión ambiental, tanto en la evaluación como, especialmente, en la fiscalización. Del discurso del efímero expremier Cateriano y de las pre publicaciones de proyectos normativos, se puede identificar la intención de una mayor reforma legal y reglamentaria en distintos sectores. 
Tabla 3

\begin{tabular}{|c|c|}
\hline \multicolumn{2}{|r|}{ Propuestas Normativas de la Reactivación Económica } \\
\hline \multirow{2}{*}{$\begin{array}{l}\text { Reactivación } \\
\text { económica }\end{array}$} & Modificación del Reglamento de regalías y retribuciones. \\
\hline & $\begin{array}{l}\text { Modificación del Reglamento de Seguridad para las actividades de } \\
\text { hidrocarburos y las medidas para la seguridad del transporte de GLP. }\end{array}$ \\
\hline \multirow[t]{2}{*}{$\begin{array}{l}\text { Reactivación del } \\
\text { sector minero }\end{array}$} & $\begin{array}{l}\text { Decreto de urgencia para facultar de manera excepcional al Ministerio } \\
\text { de Energía y Minas el financiamiento de estudios de preinversión y } \\
\text { expedientes técnicos de proyectos de inversión pública a cargo de } \\
\text { gobiernos regionales y locales principalmente en el corredor minero, } \\
\text { durante el presente año fiscal. }\end{array}$ \\
\hline & Reglamento de cierre de minas. \\
\hline \multirow{4}{*}{$\begin{array}{l}\text { Reactivación } \\
\text { del sector } \\
\text { hidrocarburos }\end{array}$} & Proyecto de modificación de Ley Orgánica de Hidrocarburos. \\
\hline & $\begin{array}{l}\text { Modificación del reglamento para la protección ambiental en las } \\
\text { actividades de hidrocarburos. }\end{array}$ \\
\hline & $\begin{array}{l}\text { Actualización de los reglamentos de Exploración y Explotación } \\
\text { de Hidrocarburos, y de Calificación de Interesados para realizar la } \\
\text { Exploración y Explotación de hidrocarburos. }\end{array}$ \\
\hline & $\begin{array}{l}\text { RM 171-2020-MINEM/DM, que dispone la publicación del Proyecto } \\
\text { de «Decreto Supremo que aprueba el Reglamento de Calificación } \\
\text { de Interesados para la Realización de Actividades de Exploración y } \\
\text { Explotación o Explotación de Hidrocarburos». }\end{array}$ \\
\hline $\begin{array}{l}\text { Reactivación del } \\
\text { sector forestal }\end{array}$ & Propuesta de Decreto Legislativo de reactivación del sector forestal. \\
\hline \multirow[t]{2}{*}{ Gestión ambiental } & $\begin{array}{l}\text { Simplificación de procedimientos Autoridad Nacional del Agua } \\
\text { (ANA) como para operaciones mineras y de hidrocarburos. }\end{array}$ \\
\hline & $\begin{array}{l}\text { RM 143- 2020- MINAM, se dispone la publicación del Proyecto de } \\
\text { Decreto Supremo que incorpora artículos en el Capítulo IV del Título } \\
\text { Segundo y modifica el Subcapítulo I del Capítulo IV del Título Tercero } \\
\text { del Reglamento de la Ley de Âreas Naturales Protegidas. }\end{array}$ \\
\hline
\end{tabular}

Fuente: Portugal y Sembrero (2020). Elaboración propia

Para el caso de las propuestas normativas, destacan la del sector hidrocarburos y forestal, la regulación del recurso hídrico, así como la de gestión de áreas protegidas. Nuestro análisis se enfocará en el cruce entre los marcos legales de reactivación económica sobre infraestructura y minero, y su afectación en la gestión ambiental y social de los proyectos; especialmente en la evaluación y fiscalización ambiental. Nos focalizaremos en los principales cambios legales que afectarían el ejercicio de derechos o aumentarían potenciales riesgos ambientales y sociales. 


\section{Reactivación con derechos}

Una de las principales preocupaciones se ha centrado en la virtualización de la participación ciudadana durante la evaluación ambiental y el desarrollo del proyecto de inversión pública, privada o mixta, conocido como monitoreo ambiental comunitario. La participación en la sociedad es relevante para influir en la institucionalidad pública, donde el sector empresarial y los medios de comunicación son privilegiados para arropar al Perú con herramientas necesarias en políticas para el desarrollo económico (Ganoza y Stiglich 2015: 135) y, obviamente, influenciando en las decisiones estatales. Sin embargo, el marco legal se ha cambiado también por la presión local de pueblos indígenas y comunidades in situ, para que sus intereses y preocupaciones sean incluidos, en particular, al momento de ejecutar proyectos y actividades económicas en sus tierras o en recursos naturales que los puedan afectar.

En ese sentido, uno de los temas que más preocupa en el proceso de reactivación económica es la participación ciudadana relacionada a la implementación de las decisiones en la gestión de los recursos naturales, es decir, la que está enfocada en la evaluación del impacto ambiental de las operaciones extractivas, como y de manera especial, en infraestructura, en minería e hidrocarburos. Durante los últimos veinte años, se registra un avance «centímetro a centímetro» de una serie de mecanismos que permiten dar seguridad política y legitimidad social a los proyectos de inversión (extractivos, infraestructura) que se desarrollan en tierras de comunidades y ciudadanos rurales. Desde la participación de audiencias públicas de presentación del Estudio de Impacto Ambiental (EIA), los talleres informativos y el monitoreo ambiental comunitario, se ha comenzado a hablar de una «gobernanza territorial» y «democracia ambiental» (Monge 2013: 85-7).

En primer lugar, debemos analizar el decreto legislativo 1500 publicado el 11 de mayo de 2020, norma que «establece medidas especiales para reactivar, mejorar y optimizar la ejecución de los proyectos de inversión pública, privada y público-privada, ante el impacto de la pandemia producida por el COVID-19». Uno de los objetivos que plantea la norma es facilitar la implementación de proyectos de inversión incluidos en el plan nacional de infraestructura y competitividad, como servicios públicos; es decir, construcción de carreteras, aeropuertos, proyectos de energía y masificación de gas. El recientemente cuestionado proyecto Hidrovía Amazónica está incluido en este paquete. Asimismo, que las disposiciones de esta norma también puedan ser aplicadas en minería e hidrocarburos.

Este decreto legislativo plantea que la participación ciudadana en materia ambiental sea virtual en las fases de elaboración y evaluación del EIA de los proyectos de inversión, a través de la suspensión de los mecanismos de 
participación ciudadana presenciales como talleres, audiencias y llamando al uso de herramientas virtuales para su adecuación ${ }^{7}$.

Tal como sostienen Portugal y Sembrero, esta disposición vulneraría

(...) el derecho a la participación ciudadana al no tomar en cuenta realidades como las brechas energéticas y tecnológicas (falta de electricidad e internet en varios pueblos indígenas amazónicos), intercultural (diferentes idiomas) y de comunicación (lejanía de las comunidades) que se dan en las comunidades amazónicas (2020: 5).

En ese sentido, la norma desconocería tanto el contexto de la propia pandemia, así como las limitaciones de comunicación que tienen muchos actores locales (tanto pueblos indígenas como comunidades locales) para acceder a la comunicación virtual. Por ello, es necesario mayor detalle y comprensión de la aplicación de esta disposición, tanto en los proyectos futuros como los previos a la cuarentena, tomando en cuenta que en los próximos meses se deben retomar los procesos de evaluación ambiental de proyectos de servicios públicos, como carreteras o cualquier obra pública relacionada a la recuperación económica.

\section{Preocupaciones ambientales}

\subsection{Los cambios en evaluación y fiscalización ambiental}

La mayor preocupación se centra en dos temas ambientales: evaluación y fiscalización ambiental. Como hemos antedicho, el decreto legislativo 1500 menciona los medios de participación ciudadana «virtuales» o la ampliación de título habilitantes (artículo 4$)^{8}$, pero también permite el aplazamiento y

\footnotetext{
7 «Artículo 6. Mecanismos de participación ciudadana (...) los mecanismos de participación ciudadana se adecúan a las características particulares de cada proyecto, de la población que participa y del entorno donde se ubica, pudiendo utilizar medios electrónicos, virtuales u otros medios de comunicación, según sea posible, y así lo determine la autoridad competente en la evaluación del plan de participación ciudadana o en su modificación; o por el titular, previa coordinación con la autoridad ambiental, cuando no sea exigible el plan antes mencionado; considerando: i) que la población pueda contar efectiva y oportunamente con la información del proyecto de inversión, ii) que el canal de recepción de aportes, sugerencias y comentarios esté disponible durante el periodo que tome la participación ciudadana, iii) que se identifique al ciudadano/a que interviene en el proceso de participación y iv) que este último tenga la posibilidad de comunicar sus aportes, sugerencias y comentarios; cumpliendo las disposiciones contenidas en las normas vigentes (...)».

8 «Artículo 4. Vigencia de títulos habilitantes y de las certificaciones ambientales. 4.1. Las autorizaciones, permisos, licencias y cualquier otro título habilitante que tenga vigencia temporal, así como las certificaciones ambientales (...) en infraestructura pública o servicios públicos, cuya vigencia culmine hasta el 31 de diciembre de 2020, se mantienen vigentes por doce (12) meses posteriores a la fecha de su vencimiento».
} 
fraccionamiento de multas (artículo 8)ำ, la suspensión de la exigibilidad de presentación e informes ambientales relacionado a la fiscalización ambiental (artículo 7) ${ }^{10}$, y brindar facilidades para la elaboración de líneas base para Estudios de Impacto Ambiental, lo que incluye trabajo en campo (artículo 5) ${ }^{11}$.

En cuanto a la evaluación ambiental y las facilidades de trabajo de campo para establecer la línea de base, esto se ha regulado en mucho más detalle (resolución ministerial 108-2020-MINAM) ${ }^{12}$, disponiéndose la priorización de información secundaria para la elaboración de la línea base de instrumentos de gestión ambiental. Lo cierto es que, en función a la flexibilización de la elaboración de los estudios de impacto ambiental, podría darse un riesgo potencial de baja calidad en el análisis de impactos y propuestas de prevención, o también potenciales contagios a nivel de comunidades, si no se monitorea correctamente dicho trabajo de campo.

En el caso del fraccionamiento y aplazamiento de la exigibilidad del pago de las multas impuestas, el OEFA aprobó la resolución de consejo directivo 007-2020OEFA/CD, «Procedimiento de aplazamiento de la exigibilidad del pago de multas impuestas por el Organismo de Evaluación y Fiscalización Ambiental - OEFA en el marco de la Emergencia Nacional», la cual amplía el alcance a toda persona natural o jurídica que desarrolla actividades económicas sujetas al ámbito de la competencia del OEFA (artículo 2), mientras que el decreto legislativo 1500 solo regulaba el fraccionamiento y aplazamiento de pago de multas a proyectos de inversión pública, privada y público-privada, en infraestructura pública y servicios públicos. Esta modificación permite que se incluyan sectores como hidrocarburos y minería.

En cuanto a la exoneración a los titulares de los proyectos, de presentar reportes, monitoreos y cualquier otra información de carácter ambiental o social,

\footnotetext{
9 «Artículo 8. Procedimiento de fraccionamiento y aplazamiento de la exigibilidad del pago de multas impuestas por el Organismo de Evaluación y Fiscalización Ambiental. (...) el Organismo de Evaluación y Fiscalización Ambiental - OEFA regula el procedimiento y las reglas para el fraccionamiento y aplazamiento de la exigibilidad del pago de las multas impuestas, dentro del plazo de treinta (30) días hábiles contados desde la entrada en vigencia del presente Decreto Legislativo. Para todos los supuestos mencionados, la regulación que apruebe el OEFA contendrá medidas que garanticen el pago de multas, sin requerir el otorgamiento de garantías ni el pago de intereses».

10 «Artículo 7. Reportes de información de carácter ambiental. 7.1. Exonerase a los administrados de la obligación de presentar a las entidades con competencia ambiental, los reportes, monitoreos y cualquier otra información de carácter ambiental o social, que implique trabajo de campo, así como de la realización de actividades necesarias para dicho fin; (...)».

11 «Artículo 5. Participación en el acompañamiento en la elaboración de la línea base del Estudio de Impacto Ambiental. 5.1. La autoridad ambiental competente requiere la participación obligatoria de los opinantes técnicos vinculantes que considere pertinentes en la etapa de elaboración de la línea base. La decisión de participar en el acompañamiento de las actividades de campo es adoptada directamente por la autoridad ambiental competente en los proyectos bajo el ámbito de su competencia, sobre la base de las coordinaciones realizadas con las entidades involucradas en función a las características técnicas ambientales del proyecto. El titular informa a la autoridad ambiental competente de manera oportuna el inicio de las actividades de campo cumpliendo lo señalado en la normatividad vigente (...)». 
el OEFA en la resolución de consejo directivo 008-2020-OEFA/CD aprueba el «Reglamento de Acciones de Fiscalización Ambiental y seguimiento y verificación a Entidades de Fiscalización Ambiental del Organismo de Evaluación y Fiscalización Ambiental - OEFA durante el Estado de Emergencia Sanitaria». Al igual que en el anterior caso, esta norma amplía el supuesto de suspensión de información ambiental desde el 16 de marzo.

Asimismo, esta resolución señala que la fiscalización ha de ser realizada por el OEFA en temas de residuos sólidos municipales, infraestructuras de residuos sólidos y en áreas degradadas para recuperación o reconversión; actividades esenciales durante la emergencia sanitaria; emergencias ambientales o catastróficas; ante un inminente peligro o alto riesgo de producirse un daño grave al ambiente; a la salud de las personas y a las acciones destinadas a mitigar las causas que generen la degradación o daño ambiental; actividades que vienen desarrollándose aún sin contar con el registro SICOVID-19; reinicio de actividades por parte del administrado; y cuando el administrado manifieste su conformidad ante el OEFA de que se desarrollen las funciones de fiscalización ambiental. Ello sin óbice de la función supervisora y preventiva del OEFA ante cualquier potencial daño al ambiente y ser humano (artículo 6.3.1).

Es importante que esta regulación permita al OEFA cumplir con sus funciones de supervisión y fiscalización de las obligaciones ambientales en tiempos de pandemia, aunque esta función debió mantenerse desde el inicio de la cuarentena «para una mayor claridad de las poblaciones del área de influencia, de las empresas y de sociedad civil» (Portugal y Sembrero 2020: 6).

\subsection{La gestión de áreas protegidas}

Una segunda gran preocupación ha estado centrada en la gestión de áreas protegidas. Póveda recomendó una alta participación de distintos grupos interesados, en todos los niveles de gestión de áreas protegidas (2006: 378), de una manera flexible y hasta llega a recomendar «acuerdos de promoción y cogestión de áreas protegidas con ONG y con el sector privado sobre la base de resultados concretos» (2006: 379). En todos estos años de avance de la gestión de estas, se ha tratado de buscar acuerdos y balances con la población local, pueblos indígenas y el sector privado. Desde la elaboración del Plan Director del Sistema Nacional de Áreas Naturales Protegidas por el Estado (SINANPE) hasta la implementación de los planes maestros de cada área protegida, ha sido un desafío congeniar con los derechos de propiedad privados y comunales, así como las concesiones y otros títulos otorgados por el Estado para aprovechar recursos naturales en área protegidas.

El 27 de julio de este año, el Ministerio del Ambiente publicó un proyecto normativo (resolución ministerial143- 2020-MINAM ${ }^{13}$ ) para modificar el

\footnotetext{
${ }_{13}$ El nombre del proyecto es «Proyecto de Decreto Supremo que incorpora artículos en el capítulo IV del Título Segundo y modifica el Subcapítulo I del Capítulo IV del Título Tercero del Reglamento de la Ley de Áreas Naturales Protegidas aprobado por Decreto Supremo Nº38-2001-AG».
} 
reglamento de la Ley 26834 de áreas protegidas, cuyo fin sería promover la convivencia pacífica y armoniosa de actividades en áreas protegidas, resolviendo las antinomias entre la conservación y las concesiones, especialmente para las actividades en minería e hidrocarburos.

Para que la gestión territorial de las áreas protegidas pueda desenvolverse de manera eficiente, han tenido que pasar diversas experiencias y conflictos alrededor de ella. Existió todo un proceso complejo alrededor de la implementación de los estudios de compatibilidad en la década pasada (Carhuatocto 2010: 157-61). Al parecer, eso no fue suficiente porque ha sido necesario presentar una propuesta legal más detallada para regular cómo las operaciones existentes conviven en áreas protegidas, siendo respetados sus «derechos previos» a la creación de las áreas protegidas cuando estos se superponen, pero «adecuados» a los fines y demás criterios de gestión, ya que el derecho de uso del recurso natural se realizará en un área donde el Estado peruano ha decidido que debe ser destinada para su conservación. No es que en todas las áreas ello sea incompatible, pero en las que sí es posible, como en las áreas protegidas de uso directo, las actividades económicas tienen que adecuarse a criterios técnicos y de gestión de dicha área (plan maestro, zonificación, los objetivos de la propia área).

El proyecto normativo del MINAM ${ }^{14}$ cambia ese equilibrio y la primacía de la conservación de la biodiversidad se elimina a favor de la preeminencia de la inversión perfeccionada en la elaboración del plan maestro y en una posible afectación a la gestión del área protegida. Es decir, no se aprobaría plan maestro alguno si no hay "acuerdo previo» con los derechos preexistentes o posteriores a la creación del área protegida (incluye derechos de propiedad). De manera tácita, el Estado renuncia a su autoritas, a su poder y al mandato establecido por la Constitución y la ley de conservar la biodiversidad para obtener, entendemos, mayor eficacia en la gestión ante una situación de superposición de derechos que necesita equilibrarse o que podría representar desafíos en conservar y aprovechar un recurso natural.

Ciertamente, si el autoritas se pierde, estamos frente a un cambio de la gestión de los recursos naturales, pues nos encontramos en una situación sui generis que va más allá de los efectos jurídicos de la participación ciudadana durante la evaluación ambiental o de la propia consulta previa. Se ha configurado un «derecho a veto» que gozarían los derechos preexistentes; es decir, si un propietario o un titular de concesión no llega a un acuerdo con la autoridad, no se puede elaborar el plan maestro del área protegida, por lo que no puede gestionarse y, además, obliga al funcionario que lleva dicho proceso de participación a que, sí

14 «37B.5 Para la elaboración del Plan Maestro, el SERNANP y los Gobiernos Regionales deberán (...) identificar y respetar los derechos adquiridos con anterioridad al establecimiento del Área Natural Protegida o Área de Conservación Regional, detallando las actividades que realiza cada titular de derecho, su antigüedad, y los títulos habilitantes que corresponda. Asimismo, en el Plan Maestro deberán detallarse las medidas adoptadas para garantizar el ejercicio de los derechos adquiridos con anterioridad al establecimiento del ANP o ACR, bajo sanción de nulidad. La autoridad proponente suscribirá acuerdos con los titulares de derechos en las áreas, para asegurar el ejercicio de sus derechos sea compatible con el Plan Maestro». 
o sí, deba lograr los acuerdos, al ser el único camino para la aprobación del plan maestro, puesto que uno de los requisitos para la validez de los planes maestros es incluir los acuerdos con titulares de los derechos preexistentes. De cierta manera, el Estado, después de 27 años de gestión de las áreas protegidas, renuncia pragmáticamente a su poder de gestión y a la primacía de la conservación de la biodiversidad, para ponerse al mismo nivel del privado. Lo que se entiende es un cambio para reactivar la economía del país, aunque no hay evidencia material de dicho efecto.

\section{Conclusiones}

Podríamos seguir manteniéndonos de espaldas a las advertencias sobre los efectos del cambio climático (Welzer 2010), de hecho, hace ya más de dos décadas, el Panel Intergubernamental de Cambio Climático (IPPC) sostenía que el cambio climático aumentaría problemas alimentarios y de desnutrición, así como «la propagación de enfermedades contagiosas» (Welzer 2010: 129). El COVID-19 se ha presentado de manera breve en algo similar a la historia del cambio climático: negación, negligencia y cinismo en menos de seis meses. Sin embargo, no es posible mantener ese escepticismo generacional, esa negligencia cómplice de las clases medias o el dolo criminal de cierto sector empresarial que aprovecha la crisis para mantener su margen de ganancia.

Es más que probable que la crisis del COVID-19 nos obligue a replantear un nuevo pacto social, incluso a aceptar «la precariedad de las regiones» (Vergara, 2019: 94). Sacrificar «la futura salud de muchos, por el hambre de hoy» y acabar la cuarentena por la presión de las elites empresariales de nuestro país incluirá también una transformación abrupta del capital natural en capital social, con un costo social y político considerable. Seguir insistiendo en el dogma de la sostenibilidad del «sistema económico en cuanto tal» (Garcés 2019: 21) es un error capital si no queremos seguir sufriendo los estragos externos e internos y que estos terminen por acabar nuestra convivencia como sociedad.

Lo más cuestionable es el rol del sector empresarial, que muestra cierta inconsistencia con una visión a largo plazo de país, especialmente en incentivos económicos a través de los cambios legales en materia ambiental. Lerner ya lo decía en 2013 en la Conferencia Minera PeruMin: «hay que tener en cuenta cuál es la finalidad de la actividad económica y comprender que la racionalidad de la ganancia no puede contradecir la existencia de otros bienes que son necesarios para la convivencia» (2017: 149); en este caso, pensando en los intereses económicos del presente, sin tomar en cuenta los intereses de todos en el futuro; en este caso, en el impacto ambiental de "una carrera hacia el fondo». Es decir, una dilución de nuestra capacidad para controlar, prevenir, supervisar, promover y sancionar actividades económicas que no se adecuan a nuestra visión de desarrollo sostenible. 0, peor aún, mantener una suerte de equilibrio en evaluación y fiscalización ambiental o en la conservación de biodiversidad. 
La construcción de una institucionalidad ambiental en la última década no será cuestionada, pero sí las herramientas con las que cuentan los ciudadanos para asegurar una calidad de la gestión ambiental, la conservación de la biodiversidad y el aprovechamiento de los recursos naturales. Las reformas de 2013, conocidas como paquetazos ambientales, apuntaban a ello y de cierta manera dejaron en stand by la acentuación de muchas de estas herramientas.

Después de la cuarentena, encontramos que la decisión del Gobierno ha sido impulsar la recuperación económica mediante la flexibilidad regulatoria y ambiental, sin lineamientos claros para el ejercicio de los derechos ambientales, como el de participación ambiental, y generando potenciales riesgos de afectar la gestión de los recursos naturales, ya sea en su uso como en su conservación. En ese sentido, es necesario que se precisen aún los alcances normativos y procedimentales de estos cambios, que permitan que la función ambiental de los distintos órganos pueda operar con la finalidad de hacer cumplir los fines de política ambiental establecida por la Constitución y la legislación ambiental precedente. Facilitar la inversión ahora, no representa una ganancia sostenible porque cualquier riesgo y su materialización posterior pasará factura en el balance de suma y resta de lo que representa para nuestro crecimiento económico.

Estamos ante un dilema que, sin conciencia y participación de todos, es difícil de asumir; que sin transparencia de quién y cómo se transforma el capital natural en bienestar humano, es difícil de aceptar. No es solo la falta de diálogo, sino que la reactivación iniciada en julio por presión del sector empresarial y los miles de desempleados se ha llevado sin medir el grado de avance de la pandemia. En agosto se reportaron picos de muertes y contagiados que llegaron a más de 25 mil muertos y 600 mil contagiados (AS Perú 2020). Citando a Lerner, si «el ímpetu lucrativo puede prevalecer sobre la consciencia del daño que la acción puede causar» (2017: 147), el costo humano y económico será más alto para todo el país, para los ciudadanos y la naturaleza. Lo cierto es que no hemos aprendido nada de los conflictos políticos, sociales y ambientales vividos en los últimos cincuenta años, menos aún de sus impactos.

\section{Referencias}

ANC, CAAAP, CEPES, CONADES, CNDH, Cooperacción, DAR, Forum, Red Muqui (2014). Impactos, intereses y beneficiarios de la Ley № 30230. Medidas tributarias, simplificación de procedimientos y permisos para la promoción y dinamización de la inversión en el país. http://www.psf.org.pe/institucional/ wp-content/uploads/2014/10/impactos-intereses-beneficiarios-30230final.pdf

Alarco, G. (2017). Políticas de inversión y crecimiento económico: mitos y realidades. En E. Toche (Comp.), Perú hoy. El arte del desgobierno (pp. 279300). Desco. 
Alarco, G., Castillo, C. y Leiva, F. (2019). Riqueza y desigualdad en el Perú. Desco.

AS Perú (28 de octubre 2020). Coronavirus en Perú: resumen y casos del 28 de Agosto. Consultado el 20 de agosto de 2020. https://peru.as.com/ peru/2020/08/28/actualidad/1598612350_255112.html

Calle, I., Mora, C., Baldovino, S., Araujo, J. P. y Capella, J. L. (2020). Análisis de la Sociedad Peruana de Derecho Ambiental (SPDA) sobre la sentencia del Tribunal Constitucional que resuelve la demanda de inconstitucionalidad interpuesta contra varios artículos de la Ley 30230, que establece medidas tributarias, simplificación de procedimientos y permisos para la promoción y dinamización de la inversión en el país. SPDA. https://spda.org.pe/?wpfb_ $\mathrm{dl}=4592$

Carhuatocto, H. (2010). Epílogo: Rumbo a los criterios de compatibilidad de áreas naturales protegidas. En C. Gamboa (Ed.). Hidrocarburos y Amazonia Peruana: ¿Superposición de derechos u oportunidades para el desarrollo sostenible? (pp. 157-162). DAR.

Chávez, S. (2018). Operación Lava Jato. Brasilera y peruana. Crónica de un sistema corrupto institucionalizado. Lluvia Editores.

Congreso de la República (s.f.). http://www.congreso.gob.pe/comisiones2020/ RREE/DocumentosEscazu/

De Echave, J. y Flores, C. (2020). Minería y tributación en tiempos de pre y postpandemia. Oxfam. CooperAcción.

Durand, F. (2016). Cuando el poder extractivo captura el Estado. Lobbies, puertas giratorias y paquetazo ambiental en Perú. Oxfam.

Durand, F. (2018). Odebrecht. La empresa que capturaba gobiernos. Fondo Editorial PUCP. Oxfam.

Gamboa, C. (2017). Manchándose las manos: el Banco Mundial y el paquetazo ambiental. En E. Toche (Comp.). Perú Hoy: el arte del desgobierno (pp.154168). Desco.

Ganoza, C. y Stiglich, A. (2015). El Perú está calato. El falso milagro de la economía peruana y las trampas que amenazan nuestro progreso. Editorial Planeta.

Garcés, M. (2019). Condición póstuma o el tiempo del todo se acaba. Nueva Sociedad, 283: 16-27. https://nuso.org/articulo/condicion-postuma-o-eltiempo-del-todo-se-acaba/

Gestión (4 de mayo 2020a). Confiep sobre protocolos de seguridad: «Están llenos de requisitos, parece para un país europeo». Diario gestión. Consultado el 20 de agosto de 2020. https://gestion.pe/economia/coronavirus-perupresidenta-de-confiep-sobre-protocolos-de-seguridad-estan-lleno-derequisitos-parece-para-un-pais-europeo-covid-19-nndc-noticia/

Gestión (22 de julio 2020b). SNMPE considera innecesario aprobar proyecto de ley sobre intangibilidad de pueblos indígenas. Gestión. Consultado el 20 de agosto de 2020. https://gestion.pe/economia/snmpe-considerainnecesario-aprobar-proyecto-de-ley-sobre-intangibilidad-de-pueblosindigenas-nndc-noticia/ 
Gudynas, E. (2012). La dimensión continental y global de las transiciones hacia las alternativas al desarrollo. En A. Alayza y E. Gudynas (Eds.), Transiciones y alternativas al extractivismo en la región andina. Una mirada desde Bolivia, Ecuador y Perú (pp. 101-129). RedGE/CEPES.

Lerner, S. (2017). Responsabilidad social empresarial. Revista Kawsaypacha, 1: 139-153. https://doi.org/10.18800/kawsaypacha.201701.005

Machado, R. (2014). Hacia la diversificación y sofisticación productiva en el Perú. Oxfam América.

MINSA 2020: MINSA (2020). I. Datos Abiertos Minsa - Covid-19. En Datos Abiertos Minsa y Gestión del Conocimiento en Covid-19. Consultado 20 de agosto de 2020. agosto). https://www.minsa.gob.pe/datosabiertos/?tipo=1\&op=22

Monge, C. (2013). Industrias extractivas y gobernanza democrática de los territorios. Quehacer, 190: 80-87. https://www.desco.org.pe/recursos/ sites/indice/845/2536.pdf

Portugal, V. y Sembrero, M. (2020). Desarrollo económico con enfoque de derechos. Análisis socioambiental de las normativas de reactivación económica implementada por el gobierno peruano en respuesta a la emergencia sanitaria causada por COVID-19 (Documento de trabajo). DAR.

Póveda, R. A. (2006). Recursos Naturales. En M. Giugale, V. Fretes-Ciblis y J. L. Newman (Eds.), Perú, la oportunidad de un país diferente. Prospero, equitativo y gobernable (pp. 367-391). Banco Mundial.

RPP (9 de julio 2020). El Gobierno descarta una «consulta previa virtual» para temas de minería. RPP Noticias. Consultado el 20 de agosto de 2020. https:// rpp.pe/politica/gobierno/coronavirus-en-peru-el-gobierno-descarta-unaconsulta-previa-virtual-para-temas-de-mineria-noticia-1279108).

Solano, D., Cuba, A. y Narciso, J. (2017). Desarrollo sostenible y estándares de calidad ambiental ¿La política de regulación ambiental debe mantenerse en un país que busca sostener sus crecimiento y desarrollo económico? En E. Toche (Comp.), El arte del desgobierno, (pp. 375-398). Desco.

Quiroz, A. (2019). Historia de la corrupción en el Perú. (3 $3^{\mathrm{a}}$ ed.). IEP.

Vergara, R. (2019). Cuando la voluntad general se equivoca. Un examen de los dos últimos procesos de descentralización en el Perú. IEP.

Welzer, H. (2010). Guerras Climáticas. Por qué mataremos (y nos matarán) en el siglo XXI. Katz Editores. 